\title{
Fixed-bed column studies for the removal of hazardous malachite green dye from aqueous solution using novel nano zerovalent iron algal biocomposite
}

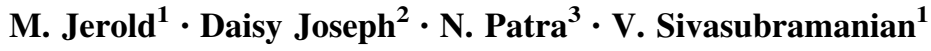

Received: 17 May 2016/ Accepted: 6 September 2016/Published online: 26 September 2016

(C) Springer International Publishing Switzerland 2016

\begin{abstract}
Sargassum swartzii, a marine alga was used as precursor for the synthesis of novel nano zerovalent iron $S$. swartzii (nZVI-SS) biocomposite for the removal of malachite green (MG) from simulated wastewater in a fixed-bed column. The performance of the biocomposite was evaluated in the fixed-bed column at various operating conditions such as bed height $(3-9 \mathrm{~cm})$, flow rate (5-15 mL/min) and initial MG concentration $(5-15 \mathrm{mg} / \mathrm{L})$. The lowest bed height $(3 \mathrm{~cm})$, lowest flow rate $(5 \mathrm{~mL} / \mathrm{min})$ and highest inlet MG concentration $(15 \mathrm{mg} / \mathrm{L})$ resulted in highest MG uptake of $0.56 \mathrm{mg} / \mathrm{g}$, compared to other experimental conditions. The column experimental data obtained at different conditions were analyzed using three different models, viz., Adam-Bohart model, Thomas model and Yoon-Nelson model. All three models provided a good breakthrough curve prediction; however, the results obtained from Thomas model and Yoon-Nelson model were more satisfactory. The well-recognized BDST model was also used for describing the effect of bed height on the breakthrough curve. The various characteristics of the biocomposite were studied using SEM, DLS, XRD, XRF and XANES. The nZVI-SS biocomposite fixed-bed column proved to be the potential biosorbent for the removal of MG from aqueous phase.
\end{abstract}

V. Sivasubramanian

siva@nitc.ac.in

1 Department of Chemical Engineering, National Institute of Technology Calicut, Kozhikode, Kerala 673 601, India

2 Nuclear Physics Division, Bhabha Atomic Research Center, Trombay, Mumbai 400 085, India

3 Atomic and Molecular Physics Division, Bhabha Atomic Research Center, Trombay, Mumbai 400 085, India
Keywords Biosorption - Dye - Algae - Zerovalent iron · Wastewater · Fixed-bed column

\section{List of symbols}

A Cross-sectional area of the bed $\left(\mathrm{cm}^{2}\right)$

$C_{\text {ad }} \quad$ Concentration of dye removal $(\mathrm{mg} / \mathrm{L})$

$C_{0} \quad$ Influent dye concentration $(\mathrm{mg} / \mathrm{L})$

$C_{t} \quad$ Effluent dye concentration $(\mathrm{mg} / \mathrm{L})$

$k_{\mathrm{AB}} \quad$ Kinetic constant (L/mg min)

$k_{\mathrm{Th}} \quad$ Thomas model constant $(\mathrm{mL} / \mathrm{min} \mathrm{mg})$

$k_{\mathrm{YN}} \quad$ Rate constant $\left(\mathrm{min}^{-1}\right)$

$m_{\text {total }} \quad$ Amount of adsorbate sent to column (g)

$N_{0} \quad$ Saturation concentration $(\mathrm{mg} / \mathrm{L})$

$q_{0} \quad$ Adsorption capacity $(\mathrm{mg} / \mathrm{g})$

$q_{\mathrm{eq}} \quad$ Equilibrium dye uptake $(\mathrm{mg} / \mathrm{g})$

$q_{\text {total }}$ Total mass of dye adsorbed (mg)

$Q \quad$ Volumetric flow rate $\left(\mathrm{cm}^{3} / \mathrm{min}\right)$

$t \quad$ Total flow time (min)

$t_{\text {total }} \quad$ Total flow time (min)

$U_{0} \quad$ Superficial velocity $(\mathrm{cm} / \mathrm{min})$

$V_{\text {eff }} \quad$ Effluent volume (mL)

$Z \quad$ Bed depth of the fixed-bed column $(\mathrm{cm})$

$Y \quad$ Percentage of MG removal (\%)

\section{Greek symbol}

$\tau$ Time required for $50 \%$ adsorbate breakthrough (min)

\section{Introduction}

Dyes and pigments are extensively used in most of the processing industries to color their products. Dyes and their metabolites are one among the severe pollutants of our environment. Perhaps, some of the dyes are known to have 
toxic as well as carcinogenic, mutagenic and teratogenic effects on aquatic life and humans. Malachite green (MG) or basic green 4 , a triphenylmethane is widely used in aquaculture as a parasiticide and in food, health, textile and other industries for various applications. In aquaculture industry, MG is used as biocide against parasitic treatment and for fungal and bacterial infections in fish and fish eggs due to its potent anti-parasitic effect [1]. It is also widely used in various industries like silk, wool, jute, leather and paper to color their products [2].

Several methods have been investigated for the removal of dyes from wastewater. Chemical precipitation is a common conventional treatment where a large quantity of chemical is necessary for the dye treatment which in turn generates a large volume of sludge [3]. Other treatment methods are ion exchange, activated carbon, filtration, electrolysis and reverse osmosis which requires high capital investment and operational costs [4]. Interestingly, biosorption was known to be a low-cost method for the treatment for dye-containing wastewater [5]. Of course, this technique has attracted most of the researchers because of its low initial cost, flexibility and simplicity of design, ease of operation, reusability of biosorbent and high efficiency. Various biosorbent materials such as bacteria, yeast, algae and other agricultural waste have been used to remove dyes from wastewater $[5,6]$. However, the constituents of biosorbents are mainly responsible for the removal of any particular pollutants from wastewater [7]. Sargassum, a marine brown alga was found to have various functional groups over the surface of the cell wall serves as excellent ligand for the sorption of ions from the aqueous solution [8, 9]. However, to enhance the biosorption capacity, there is a need for the modification of the biosorbent. Nowadays, zerovalent iron gaining much importance in the treatment of hazardous and toxic wastes [10]. Interestingly, development of biomaterials and composites in nanoscale is gaining attention for adsorption of dyes and heavy metal ions [11]. Zerovalent iron (ZVI) composites are eco-friendly cost-effective reducing agent and are reliable biosorbent for dye and heavy metals removal from wastewater.

In our previous work, nano zerovalent Sargassum swartzii (nZVI-SS) was employed as biosorbent in batch mode of operation and the results showed that nZVI-SS was promising biosorbent. Thus, present objective of the research is to investigate the practical applicability of the biosorbent in a continuous column operation. The influence of several operational parameters such as bed depth, feed flow rate and inlet dye concentration has been analyzed. Further, the fit of the experimental data to various models such as Thomas, bed depth service time (BDST), Adams-Bohart and Yoon-Nelson was subjected to describe the breakthrough curves.

\section{Materials and methods}

\section{Reagents and chemicals}

Dye (malachite green) was purchased from Nice Chemicals, India. Dye used in the present study is of commercial grade with $70 \%$ purity (oxalate form). Sodium borohydride $\left(\mathrm{NaBH}_{4}, 98 \%\right.$, Alfa Aesar), iron (III) chloride $\left(\mathrm{FeCl}_{3}, 98 \%\right.$, Alfa Aesar) were purchased and used without further purification. All other chemicals were purchased locally with at least $98 \%$ purity and used without any further purifications.

\section{Preparation of biosorbent and dye solution}

Raw S. swartzii was collected locally from Mandapam, Tamil Nadu, India. The collected seaweed was washed with distilled water for five times and subsequently dried in hot air oven at $60{ }^{\circ} \mathrm{C}$ for $24 \mathrm{~h}$. The dried biomass was chopped using mechanical grinder and sieved to a particle size of $0.5-1.0 \mathrm{~mm}$ (B.S.S Mesh No. 25). The processed biomass was protonated using $0.1 \mathrm{M} \mathrm{HCl}$. The biomass was then washed several times with distilled water to remove the excess of acid adhering onto the surface, and the protonated biomass was dried overnight at $60{ }^{\circ} \mathrm{C}$. Malachite green (MG) was selected as the model dye for the present investigation. The stock solution was prepared by dissolving $1 \mathrm{~g}$ of dye in $1000 \mathrm{~mL}$ of distilled water. Working solutions were prepared by diluting the stock solution. The maximum absorbance of malachite green is $617 \mathrm{~nm}$ and at this absorbance, dye decolorization was monitored.

\section{Synthesis and characterization of nZVI-Sargassum swartzii biocomposite}

The nanoscale zerovalent iron (nZVI)-S. swartzii biocomposite material was prepared by borohydride reduction method using $\mathrm{FeCl}_{3}$ and macroalgae (S. swartzii) in the ratio 1:1 (mass basis). The protonated biomass was added to the solution containing $0.05 \mathrm{M} \mathrm{FeCl}_{3}$ in a beaker and stirred using a magnetic stirrer for $2 \mathrm{~h}$. After a thorough mixing, $10 \mathrm{~mL}$ of $0.53 \mathrm{M} \mathrm{NaBH}_{4}$ solution was added into the above mixture and further stirred well for another $30 \mathrm{~min}$ to form precipitates. The precipitates formed were washed several times with ethanol and filtered using 0.45$\mu \mathrm{m}$ Millipore filter paper and dried at $50{ }^{\circ} \mathrm{C}$ overnight [12].

The formation of iron precipitates was observed using scanning electron microscopy (JSM - 6390LV, JEOL, USA). Dynamic light scattering (DLS) analysis was performed to determine the diameter of nZVI particles. To investigate the material structure of iron nanoparticles, the 
Fe mixture was subjected to XRD analysis (AXS D8, Bruker Kappa, USA) at $45 \mathrm{kV}$ and $30 \mathrm{~mA}$ and the scanning angle was set between $20^{\circ}$ to $60^{\circ}$ because at this scanning range the iron and iron species were covered. The scanning rate of $2.0 \% \mathrm{~min}$ was maintained throughout the analysis. The synthesized nZVI particles were subjected to XRD analysis to validate the ferrous ion in the nZVI-SS biocomposite. The X-ray fluorescence (XRF) analysis which confirms the presence of Fe in the nZVI-SS biocomposite. The reverse bias of $800 \mathrm{~V}$ was applied across the semiconductor junction of $\mathrm{Si}(\mathrm{Li})$ detector, and the resolution of the detector was $150 \mathrm{eV}$ at $5.9 \mathrm{keV}$. The nZVI-powder was placed in front of an XRF spectrometer. For the excitation of the samples, $\mathrm{Cd}^{109}$ radioactive source was employed in annular geometry to prevent the direct exposure of the excitation source to the detector and minimize backscatter interference. The $\mathrm{Cd}^{109}$ emits $\mathrm{Ag} \mathrm{K}$ X-ray (energy $22.25 \mathrm{keV})$. The $\mathrm{X}$-ray spectra were recorded for a counting time of $2000 \mathrm{~s}$ and stored in a PC based multichannel analyzer for further offline analysis. Further, to understand the valency of the iron, the X-ray absorption near edge structure (XANES) spectra of iron samples including metallic $\mathrm{Fe}, \mathrm{FeO}, \mathrm{Fe}_{2} \mathrm{O}_{3}$ and $\mathrm{Fe}_{3} \mathrm{O}_{4}$ were obtained from INDUS-II synchrotron source Raja Ramanna Centre for Advanced Technology (RRCAT), Indore, India. It gives spectra of iron samples including metallic $\mathrm{Fe}, \mathrm{FeO}, \mathrm{Fe}_{2} \mathrm{O}_{3}$ and $\mathrm{Fe}_{3} \mathrm{O}_{4}$. XANES uses synchrotron radiation to photo-ionize the core electrons of $\mathrm{Fe}$ atom and provides useful information on the valance of iron. The electron storage ring was operated with energy of $1.3 \mathrm{GeV}$ and a current of 100-200 mA. The data were collected in transmission mode with a Lytle detector in the region of $\mathrm{Fe}-\mathrm{K}$ edge $(7112 \mathrm{eV})$ at room temperature.

\section{Operation of fixed-bed column}

The fixed-bed column studies were performed using a laboratory-scale glass column with an internal diameter of $1.5 \mathrm{~cm}$ and a length of $20 \mathrm{~cm}$. Glass wool was supported, and the column was closed to maintain good liquid distribution. Column was packed with $1.5,3.0$ and $4.5 \mathrm{~g}$ of nZVI-SS to obtain a particular bed height of $3,6,9 \mathrm{~cm}$, respectively, keeping flow rate and influent MG concentration constant at $10 \mathrm{ml} / \mathrm{min}$ and $10 \mathrm{mg} / \mathrm{L}$, respectively. The MG solution of known concentrations (5, 10 and $15 \mathrm{mg} / \mathrm{L}$ ) at natural $\mathrm{pH} 10$ was pumped using peristaltic pump (Rivotek-50171 002; Rivieria, India) through the column at a desired flow rate $(5,10$ and $15 \mathrm{~mL} / \mathrm{min})$. The $\mathrm{pH}$ was adjusted using $0.1 \mathrm{~N} \mathrm{HCl} / \mathrm{NaOH}$ solution in multiparameter portable meter (Model H19829, Hanna Instruments, USA). Effluent samples were collected at regular time intervals to determine the residual dye concentration in the effluent solutions using double beam U-V spectrophotometer (2201; Systronics, India) at $617 \mathrm{~nm}$. The influent to the column was continued until there was no further adsorption, i.e., the operation was stopped when the effluent concentration exceeded a value of $\sim 99.5 \mathrm{mg} / \mathrm{L}$ or higher.

\section{Column data analysis}

The performance of the fixed-bed column is predicted based on the breakthrough curves. For determining the operation and dynamic response of a sorption column, the time for breakthrough appearance and shape of the breakthrough curve are essential characteristics. The breakthrough point is nothing but when the effluent concentration $\left(C_{t}\right)$ from the column that reaches about $0.1 \%$ of the influent concentration $\left(C_{0}\right)$. Similarly, the point where the effluent concentration reaches $\sim 99 \%$ is called the "point of column exhaustion". The breakthrough curve for a given bed depth is generally expressed in terms of the ratio $C_{t} / C_{0}$ as a function of time or volume of the effluent. The volume of the effluent, $V_{\text {eff }}(\mathrm{mL})$, can be calculated from the following equation:

$V_{\text {eff }}=Q t_{\text {total }}$

where $Q$ is the volumetric flow rate $(\mathrm{mL} / \mathrm{min})$ and $t_{\text {total }}$ is the total flow time (min).

The total mass of dye adsorbed, $q_{\text {total }}(\mathrm{mg})$, can be calculated from the area under the breakthrough curve:

$q_{\text {total }}=\frac{Q}{1000} \int_{t=0}^{t=\text { total }} C_{\text {ad }} \mathrm{d} t$

where $C_{\mathrm{ad}}$ is the concentration of dye removal $(\mathrm{mg} / \mathrm{L})$.

Equilibrium metal uptake or maximum capacity of the column, $q_{\text {e,exp }},(\mathrm{mg} / \mathrm{g})$, in the column is calculated as follows:

$q_{\mathrm{e}, \exp }=\frac{q_{\mathrm{total}}}{m}$

where $m$ is the dry weight of adsorbent in the column $(\mathrm{g})$.

Total amount of metal ion entering to the column $\left(m_{\text {total }}\right)$ is calculated from the following equation

$m_{\text {total }}=\frac{C_{0} Q t_{\text {total }}}{1000}$,

and the removal percentage of MG can be obtained using the following equation

$Y(\%)=\frac{q_{\text {total }}}{m_{\text {total }}} \times 100$ 


\section{Result and discussion}

\section{Characterization of nZVI-SS biocomposite}

The formation of iron pellets can be observed in scanning electron micrograph as shown in Fig. 1. The average diameter of iron nanoparticles observed in dynamic light scattering (DLS) is about $1734 \mathrm{~nm}$ as shown in Fig. 2. The XRD analysis report reveals the presence of zerovalent iron the mixture of nZVI-SS biocomposite as shown in Fig. 3. In the XRD spectra between $20^{\circ}$ to $50^{\circ}$ as shown in Fig. 3, peaks obtained were sharper. This peak represents the various state of Fe particle. The larger peak at 2-Theta ${ }^{\circ}$ of $\sim 45^{\circ}$ denotes the excessive occurrence of ZVI in the nZVI-SS biocomposite. The other shorter peaks represent the presence of $\mathrm{FeO}, \mathrm{Fe}_{2} \mathrm{O}_{3}$ and $\mathrm{Fe}_{3} \mathrm{O}_{4}$ [13].

The X-ray spectrum Fig. 4 shows the counts with respect to channels, and the peaks of $\mathrm{Fe}-\mathrm{K} \alpha$ and $\mathrm{Fe}-\mathrm{K} \beta$ are

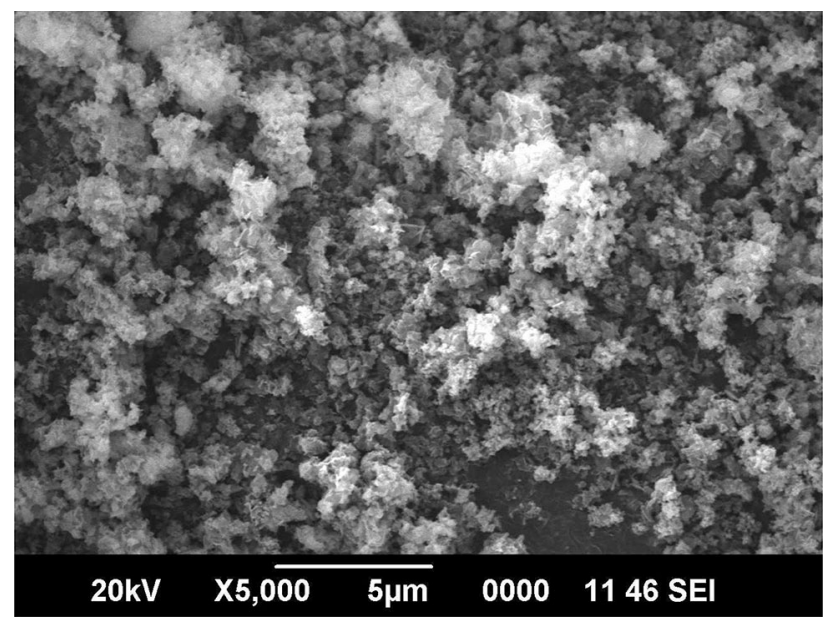

Fig. 1 Scanning electron microscopy image of nZVI

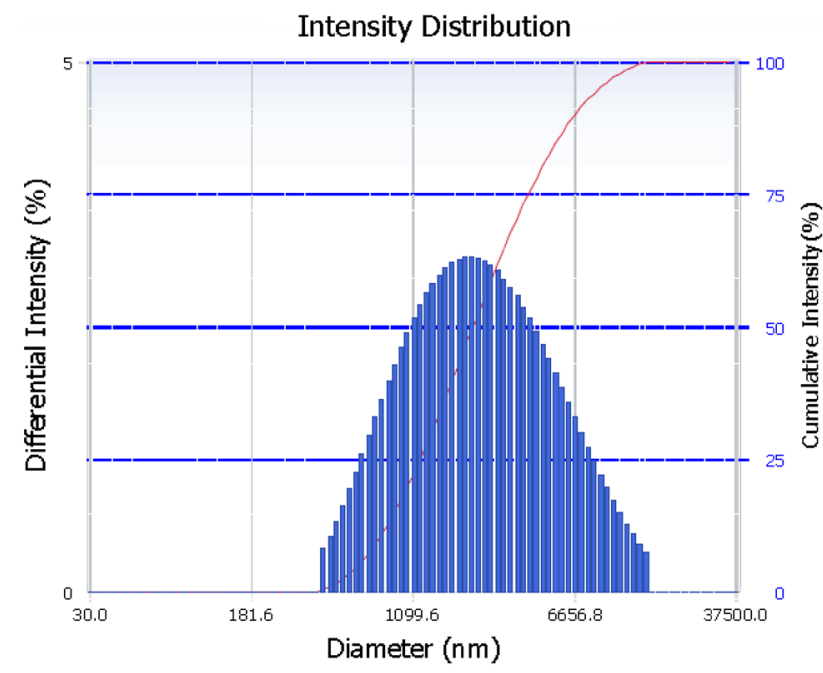

Fig. 2 Dynamic light scattering of nZVI seen with high counts. Also there are no other elements present as seen from the spectrum. Hence, it is concluded that there are only Fe particles present in the nZVI-SS biocomposite. The XANES spectrum of iron particles present in the nZVI-SS biocomposite is shown in Fig. 5. An elevation in the photon energy level from 7120 to $7180 \mathrm{eV}$ indicates the presence of both $\mathrm{FeO}$ and zerovalent iron $\left(\mathrm{Fe}^{0}\right)$. Though, the shell is largely made of iron oxides (i.e., $\mathrm{FeO}$ ), the iron nanoparticles likely to have a core of main zerovalent iron particles [14].

\section{Effect of different bed depths on breakthrough curve}

Bed height is one of the essential parameter in the column biosorption influencing the breakthrough curve packed bed column. The breakthrough curves at different bed depth are shown in Fig. 6. The retention time of MG depends on the bed depth of the nZVI-SS biocomposite. From Fig. 6, it is clear that as the bed depth increased, the retention time and the effluent volume ( $\left.V_{\text {eff }}\right)$ increased. The removal efficiency had increased trend as the mass of the biosorbent increased Table 1. This result specifies that smaller bed get saturated faster than the larger bed [15]. In the present study, maximum exhaustion time of 24 min was recorded for a highest bed depth of $9 \mathrm{~cm}$. Meanwhile, as the bed depth decreased, the axial dispersion of $\mathrm{MG}$ increased along the depth of fixed-bed column which resulted in the formation of steeper breakthrough curve. Further, the slope of the breakthrough curve decreased, as the bed depth increased, which resulted in a broadened mass transfer zone. The sorption column data were evaluated and presented in Table 1. As shown in Table 1, the bed depth has strongly influenced the biosorption capacity of MG 0.48 , 0.37 and $0.33 \mathrm{mg} / \mathrm{g}$ which was recorded at $3,6,9 \mathrm{~cm}$. Percentage of MG removal was found to increase from 60 to $62.5 \%$ as the bed height increased from 3 to $9 \mathrm{~cm}$. The decrease in MG uptake with increasing bed depth in fixedbed column may be due to the increase in the surface area of the biosorbent, and contact time was less in the case of continuous experiment [16].

\section{Effect of flow rate on breakthrough curve}

Flow rate is also another factor which influences the breakthrough. Figure 7 shows the various breakthrough curves at different flow rate of MG solution in the packed bed column. From Fig. 7, significant shrinkage of breakthrough curves was observed when the flow rate was increased from 5 to $15 \mathrm{~mL} / \mathrm{min}$. An increase in flow rate has reduced the external film mass resistance over the surface of the biosorbent which tends to decrease the residence time. Therefore, the saturation time decreased, 
Fig. 3 XRD spectra of nZVI

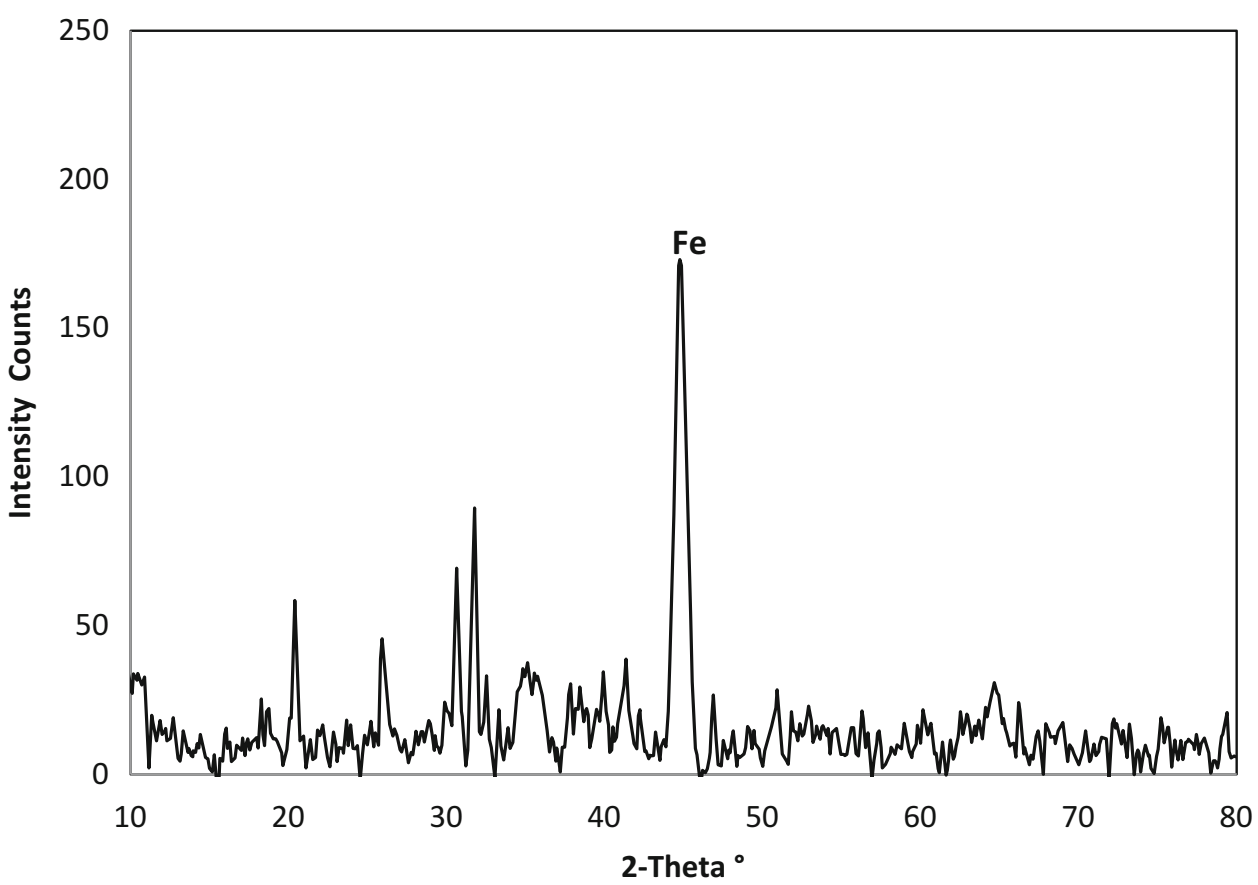

Fig. 4 X-ray fluorescence spectra of nZVI

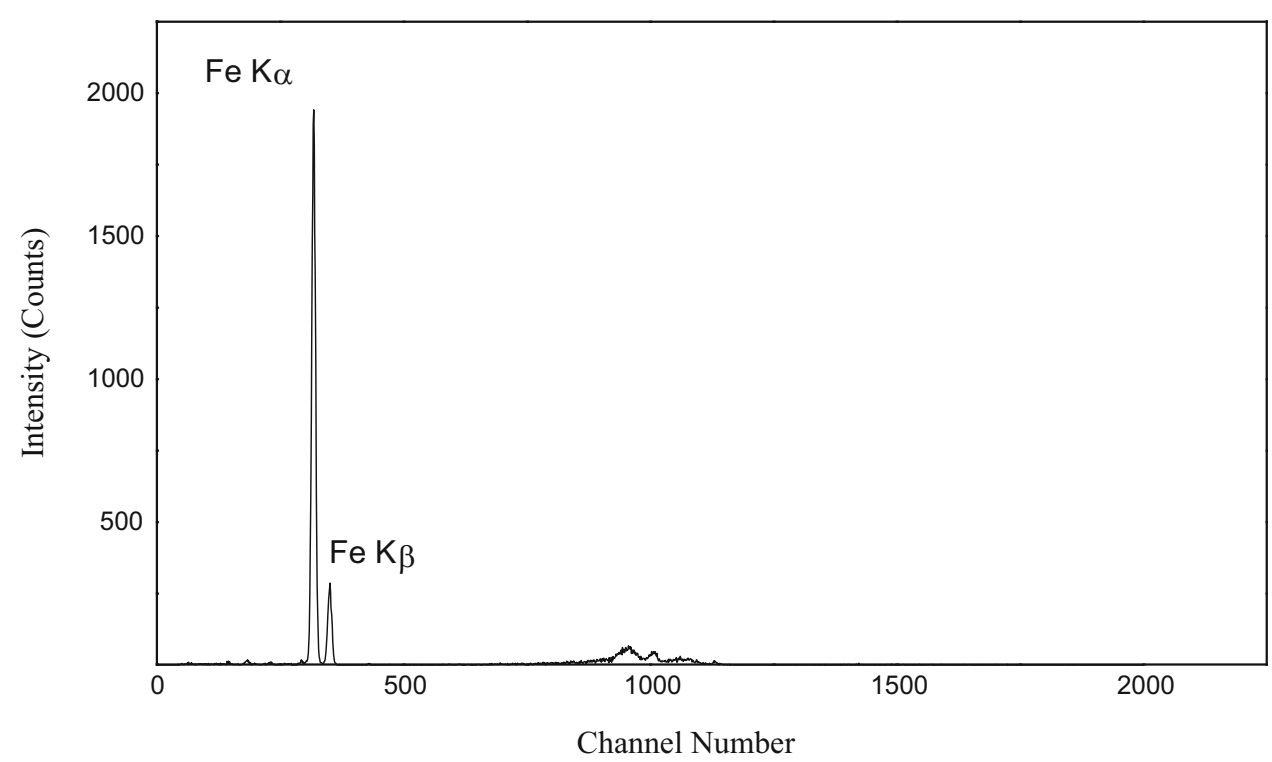

which in turn lead to the diminution in the removal efficiency. Conversely, at lower flow rate, the period of mass transfer inside the pores of the biosorbent would be increased which in turn allows the accession of more binding sites [17]. Thus, the percentage removal would be increased. As discussed, the breakthrough became steeper Fig. 7 as the flow rate increased. The biosorption capacity was strongly influenced by influent flow rate. Lower the flow rate greater the biosorption capacity and vice versa. In particular, at higher flow rate, a poor binding capacity between the functional groups of the biosorbent and the MG ions [18]. Thus, attainment of biosorption equilibrium was tragic; hence, the biosorption capacity was also limited.

\section{Effect of influent dye concentration of breakthrough curve}

In biosorption of MG to nZVI-SS biocomposite in a fixedbed column, the change in influent dye concentration seems to influence the various column parameters like breakthrough time, uptake of dye and removal efficiency. Figure 8 shows the effect of influent MG concentration on the breakthrough curves. From Fig. 8, it was noted that due to 
Fig. 5 XANES spectra of iron particles of nZVI

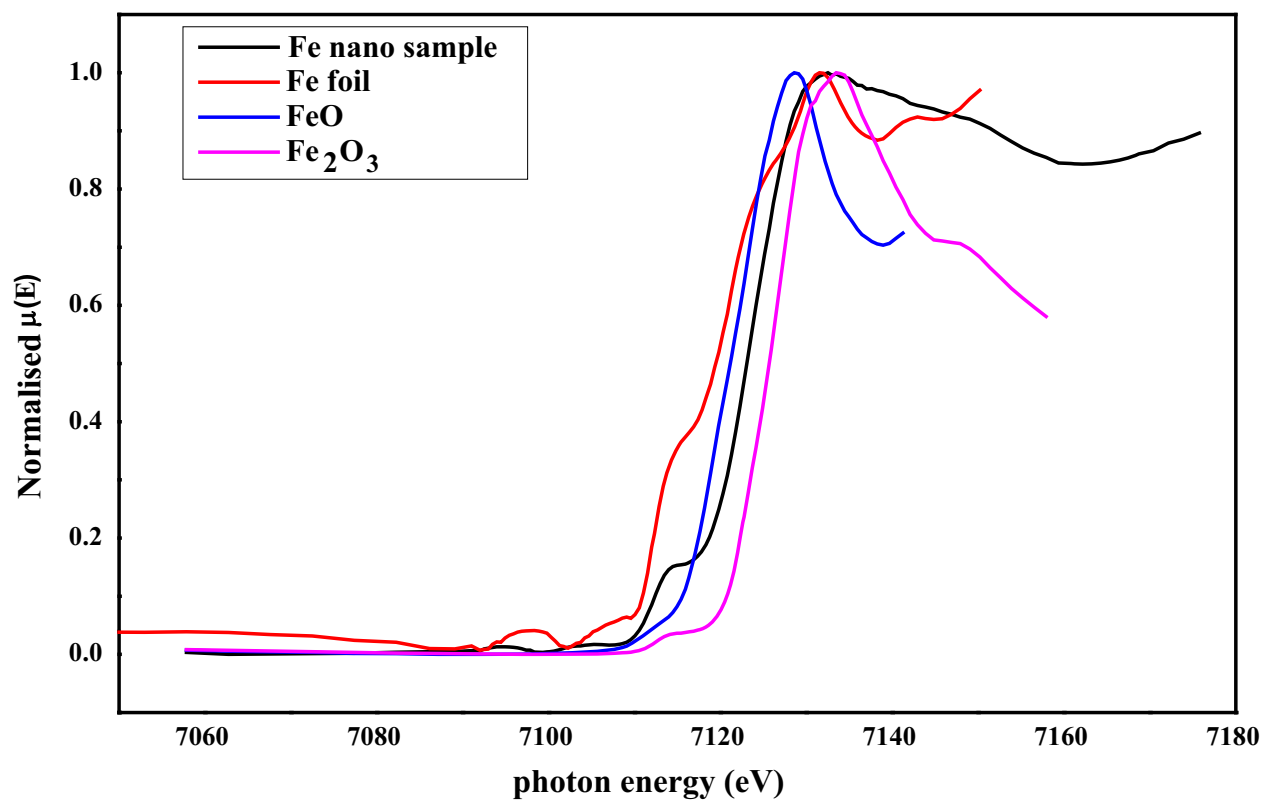

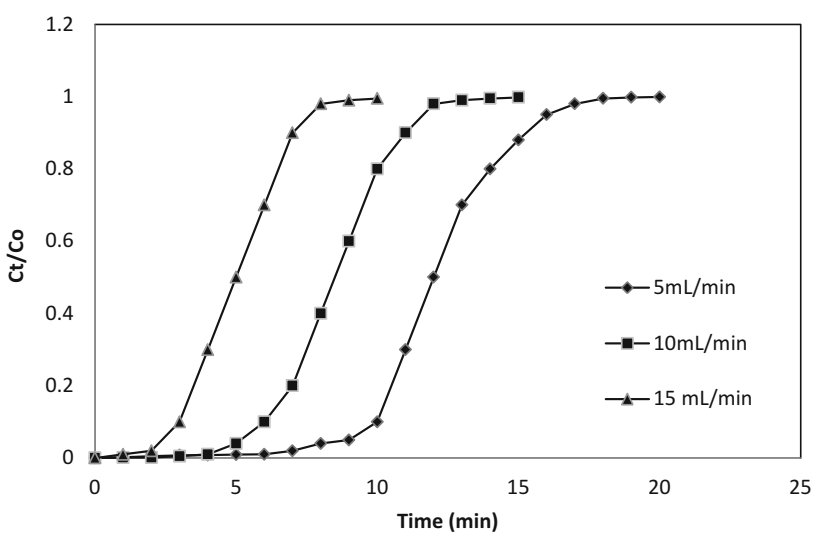

Fig. 7 Breakthrough curves for MG biosorption onto nZVI-SS biocomposite at different flow rate (bed depth: $3 \mathrm{~cm} ; 10 \mathrm{~mL} / \mathrm{min}$, $C_{0}: 10 \mathrm{mg} / \mathrm{L}$ and $\mathrm{pH} 10.0$ )

Fig. 6 Breakthrough curves for MG biosorption onto nZVI-SS biocomposite at different bed depth (flow rate: $10 \mathrm{~mL} / \mathrm{min}, C_{0}$ : $10 \mathrm{mg} / \mathrm{L}$ and $\mathrm{pH} 10.0)$

Table 1 Parameters in packed bed column for MG biosorption by nZVI-SS biocomposite

\begin{tabular}{lllllllll}
\hline$C_{0}(\mathrm{mg} / \mathrm{L})$ & $Q(\mathrm{~mL} / \mathrm{min})$ & $Z(\mathrm{~cm})$ & $t_{\text {total }}(\mathrm{min})$ & $m_{\text {total }}(\mathrm{mg})$ & $q_{\text {total }}(\mathrm{mg})$ & $q_{\mathrm{e}, \text { exp }}(\mathrm{mg} / \mathrm{g})$ & $V_{\text {eff }}(\mathrm{mL})$ & $Y(\%)$ \\
\hline 10 & 10 & 3 & 12 & 1.2 & 0.72 & 0.48 & 120 \\
10 & 10 & 6 & 20 & 2.0 & 1.11 & 0.37 & 60 \\
10 & 10 & 9 & 24 & 2.4 & 1.50 & 0.33 & 200 & 240 \\
10 & 5 & 3 & 20 & 1.0 & 0.60 & 0.4 & 62.5 \\
10 & 10 & 3 & 15 & 1.5 & 0.84 & 0.56 & 100 \\
10 & 15 & 3 & 10 & 1.5 & 0.74 & 0.49 & 150 \\
5 & 10 & 3 & 15 & 0.75 & 0.50 & 0.33 & 150 \\
10 & 10 & 3 & 12 & 1.2 & 0.73 & 0.48 & 150 \\
15 & 10 & 3 & 9 & 1.35 & 0.76 & 0.56 & 60 \\
\hline
\end{tabular}




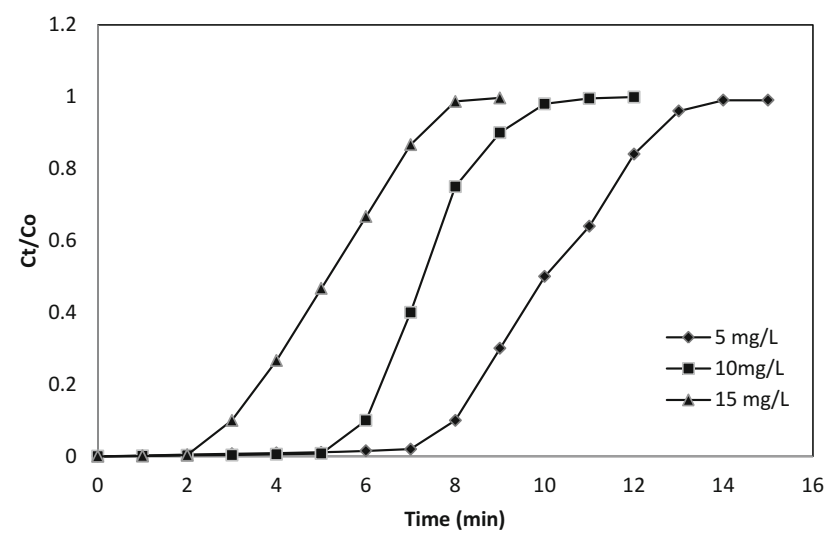

Fig. 8 Breakthrough curves for MG biosorption onto nZVI-SS biocomposite at different influent dye concentration (flow rate: $10 \mathrm{~mL} / \mathrm{min}$; bed depth: $3 \mathrm{~cm} ; 10 \mathrm{~mL} / \mathrm{min}$ and $\mathrm{pH} \mathrm{10.0)}$

an increase in the MG concentration, the biosorbent gets saturated faster which resulted in the decrease in the breakthrough time. Likewise, as the MG feeding concentration was low, the breakthrough curve and the effluent volume collected were increased. From the above discussion, obviously the biosorption capacity was also greater at higher MG concentration. This is due to the higher mass transfer rate due to an increased diffusion coefficient or mass transfer coefficient at higher influent dye concentration [19]. When the initial MG concentration is increased from 5 to $15 \mathrm{mg} / \mathrm{L}$, the biosorption capacity elevated from 0.33 to $0.56 \mathrm{mg} / \mathrm{g}$. Of course, at higher influent dye concentration, the driving force reached maximum. Therefore, it helps to overcome the mass transfer resistance [20, 21]. Meanwhile, the exhaustion time tends to decrease from min to min as the influent dye concentration increased from 5 to $15 \mathrm{mg} / \mathrm{L}$. These results demonstrated that higher inlet MG concentration allowed the biosorbent material to get saturated faster. Therefore, it is concluded that higher influent MG concentration offered an ambient driving force, relatively smaller mass transfer zone and increased sorption capacity [22].

\section{Breakthrough curve modeling}

The performance and successful design of a fixed-bed column are described through the modeling of the breakthrough curve. In a fixed-bed biosorption column, the two important characteristics determining the operation and the dynamic response from adsorption column are breakthrough time and the shape of the breakthrough curve. For the past years, several mathematical models have been proposed for describing and analyzing the experimental values, in order to develop an industrial scale adsorption column [23]. In the present investigation, four different mathematical models were proposed to predict the breakthrough curves obtained at various experimental parameters. The four models are Adams-Bohart, Thomas-Yoon models, Yoon-Nelson Model and BDST model.

\section{Adam-Bohart Model}

Bohart and Adams [24] proposed a fundamental equation based on the surface reaction theory describing the relationship between $C_{t} / C_{0}$ and $t$ in a continuous system. This model assumes that equilibrium is not instantaneous. It is used for the description of the initial part of the breakthrough curve. The expression is as follows:

$\ln \left(\frac{C_{t}}{C_{0}}\right)=k_{\mathrm{AB}} C_{0} t-k_{\mathrm{AB}} N_{0}\left(\frac{Z}{U_{0}}\right)$

where $C_{0}$ and $C_{t}$ are the influent and effluent concentration $(\mathrm{mg} / \mathrm{L})$, respectively; $k_{\mathrm{AB}}$ is the kinetic constant (L/ $\mathrm{mg} \min ), N_{0}$ is the saturation concentration $(\mathrm{mg} / \mathrm{L}), Z$ is the bed depth of the fixed-bed column $(\mathrm{cm})$, and $U_{0}$ is the superficial velocity $(\mathrm{cm} / \mathrm{min})$ defined as the ratio of the volumetric flow rate $Q\left(\mathrm{~cm}^{3} / \mathrm{min}\right)$ to the cross-sectional area of the bed $A\left(\mathrm{~cm}^{2}\right)$. The range of $t$ was taken into consideration from the beginning to the end of breakthrough. A linear plot of $\ln \left(C_{t} / C_{0}\right)$ against $t$ gives the values of the parameters $k_{\mathrm{AB}}$ and $N_{0}$. The corresponding values of $k_{\mathrm{AB}}$ and $N_{0}$ were calculated and presented in Table 2. From Table 2, it is observed that kinetic constant $\left(k_{\mathrm{AB}}\right)$ increased with increase in influent flow rate, but decreased with increasing bed depth and influent MG concentration. This indicates at initial stage overall system kinetics may be influenced by external mass transfer in the column adsorption [25].

\section{Thomas model}

Thomas model is one of the most widely used models to describe the packed bed column adsorption data [26]. This model assumes plug flow behavior in the bed. Basically, the rate driving force obeys the second-order reversible reaction kinetics. Therefore, it assumes Langmuir kinetics of adsorption-desorption and negligible axial dispersion in the column adsorption [27]. The linearized form of this model can be described by the following expression,

$\ln \left(\frac{C_{0}}{C_{t}}-1\right)=\frac{k_{\mathrm{Th}} q_{0} M}{Q}-k_{\mathrm{Th}} C_{0} t$

where $C_{0}$ is the initial metal ion concentration in the liquid phase $(\mathrm{mg} / \mathrm{L}) ; C_{t}$ is the metal concentration at time $t$ in the solution $(\mathrm{mg} / \mathrm{L}) ; k_{\mathrm{Th}}$ is the Thomas model constant $(\mathrm{mL} /$ $\min \mathrm{mg}) ; q_{0}$ is the adsorption capacity $(\mathrm{mg} / \mathrm{g}) ; \mathrm{M}$ is the amount of adsorbent in the packed bed column (g); and 
Table 2 Parameters of AdamBohart model at different experimental conditions

\begin{tabular}{llllll}
\hline$C_{0}(\mathrm{mg} / \mathrm{L})$ & $Q(\mathrm{~mL} / \mathrm{min})$ & $Z(\mathrm{~cm})$ & \multicolumn{2}{l}{ Adams-Bohart parameter } & $R^{2}$ \\
\cline { 4 - 5 } & & & $k_{\mathrm{AB}}(\mathrm{L} / \mathrm{mg} \min )$ & $N_{0}(\mathrm{mg} / \mathrm{L})$ & \\
\hline 10 & 10 & 3 & 0.0658 & 47.54 & 0.908 \\
10 & 10 & 6 & 0.0396 & 38.46 & 0.887 \\
10 & 10 & 9 & 0.0343 & 32.16 & 0.914 \\
10 & 5 & 3 & 0.0363 & 39.61 & 0.924 \\
10 & 10 & 3 & 0.0532 & 57.11 & 0.853 \\
10 & 15 & 3 & 0.0507 & 57.32 & 0.804 \\
5 & 10 & 3 & 0.1 & 31.22 & 0.939 \\
10 & 10 & 3 & 0.0734 & 47.99 & 0.896 \\
15 & 10 & & 0.0572 & 51.85 & 0.764 \\
\hline
\end{tabular}

\begin{tabular}{|c|c|c|c|c|c|}
\hline \multirow[t]{2}{*}{$C_{0}(\mathrm{mg} / \mathrm{L})$} & \multirow[t]{2}{*}{$Q(\mathrm{~mL} / \mathrm{min})$} & \multirow[t]{2}{*}{$Z(\mathrm{~cm})$} & \multicolumn{2}{|c|}{ Thomas model parameter } & \multirow[t]{2}{*}{$R^{2}$} \\
\hline & & & $k_{\mathrm{TH}}(\mathrm{mL} / \mathrm{min} \mathrm{mg})$ & $q_{0}(\mathrm{mg} / \mathrm{g})$ & \\
\hline 10 & 10 & 3 & 0.122 & 471.42 & 0.982 \\
\hline 10 & 10 & 6 & 0.077 & 364.71 & 0.974 \\
\hline 10 & 10 & 9 & 0.056 & 334.47 & 0.952 \\
\hline 10 & 5 & 3 & 0.069 & 383.96 & 0.963 \\
\hline 10 & 10 & 3 & 0.097 & 565.09 & 0.996 \\
\hline 10 & 15 & 3 & 0.114 & 503.93 & 0.992 \\
\hline 5 & 10 & 3 & 0.163 & 328.26 & 0.955 \\
\hline 10 & 10 & 3 & 0.131 & 486.25 & 0.968 \\
\hline 15 & 10 & 3 & 0.102 & 528.03 & 0.969 \\
\hline
\end{tabular}

Table 3 Parameters of Thomas model at different experimental conditions
Yoon-Nelson model for a single component system can be expressed as:

$\ln \left(\frac{C_{t}}{C_{0}-C_{t}}\right)=k_{\mathrm{YN}} t-\tau k_{\mathrm{YN}}$

where $k_{\mathrm{YN}}$ is the rate constant $\left(\mathrm{min}^{-1}\right)$ and $\tau$ is the time required for $50 \%$ adsorbate breakthrough (min). The parameter values are determined form the linear plot of $\ln \left[C_{t} /\left(C_{0}-C_{t}\right)\right]$ against $t$.

The relative constant and statistical parameters of Yoon-Nelson model obtained at various operating conditions are tabulated in Table 4. From Table 4, it was noted that the coefficient of determination was higher and shows a better goodness of fit with the experimental data. Also, from Table 4 , the rate constant $k_{\mathrm{YN}}$ increased and the $50 \%$ breakthrough time $(\tau)$ decreased with increasing both flow rate and influent MG concentration. However, when the bed depth is increased, the $\tau$ values increased, while the values of $k_{\mathrm{YN}}$ decreased [29]. Perhaps, it was due to the rapid saturation of nZVI-SS biocomposite in the column. Likewise, due to an increase in the bed depth both $\tau$ and $k_{\mathrm{YN}}$ values decreased. 
Table 4 Parameters of Yoon-Nelson at different experimental conditions

\begin{tabular}{llllrl}
\hline$C_{0}(\mathrm{mg} / \mathrm{L})$ & $Q(\mathrm{~mL} / \mathrm{min})$ & $Z(\mathrm{~cm})$ & \multicolumn{2}{l}{ Parameters } & $R^{2}$ \\
\cline { 3 - 5 } & & & $k_{\mathrm{YN}}\left(\mathrm{min}^{-1}\right)$ & $\tau(\mathrm{min})$ & \\
\hline 10 & 10 & 3 & 1.220 & 7.07 & 0.982 \\
10 & 10 & 6 & 0.770 & 10.94 & 0.974 \\
10 & 10 & 9 & 0.566 & 15.05 & 0.952 \\
10 & 5 & 3 & 0.692 & 11.51 & 0.963 \\
10 & 10 & 3 & 0.976 & 8.47 & 0.996 \\
10 & 15 & 3 & 1.144 & 5.03 & 0.992 \\
5 & 10 & 3 & 0.817 & 9.82 & 0.955 \\
10 & 10 & 3 & 1.318 & 7.24 & 0.968 \\
15 & 10 & 3 & 1.531 & 5.27 & 0.969 \\
\hline
\end{tabular}

\section{BDST model}

BDST is a model for predicting the relationship between depths and service time at different values of breakthrough. This model was proposed based on the assumption of forces like intra particle diffusion and external mass transfer resistance negligible and that the adsorbate is adsorbed onto the adsorbent surface directly [30]. The main objective of the BDST model is the estimation of column characteristics such as biosorption capacity and kinetic constant. The linearized BDST model is expressed as follows:

$t_{\mathrm{s}}=\left(\frac{N_{0} Z}{C_{0} U_{0}}\right)-\left(\frac{1}{C_{0} k_{\mathrm{a}}}\right) \ln \left(\frac{C_{0}}{C_{\mathrm{b}}}-1\right)$

where $t_{\mathrm{s}}$ is the service time (min), $u$ is the influent linear velocity of the MG solution passed through the bed $(\mathrm{cm} /$ $\min ), N_{0}$ is the saturation concentration of bed $(\mathrm{mg} / \mathrm{L}), Z$ is the bed depth $(\mathrm{cm})$, and $k_{\mathrm{a}}$ is the rate constant in BDST model (L/mg min). A plot of $t_{\mathrm{s}}$ against bed depth $Z$ derived from BDST equation is used to determine the constant values $N_{0}$ and $k_{\mathrm{a}}$ from the slope and intercept, respectively.

The experimental results obtained from MG biosorption in a column by nZVI-SS biocomposite were fitted to the BDST model to determine the biosorption capacity and kinetic constant. The $R^{2}$ value was found to be 0.964 which indicates the validity of BDST model for the packed bed biosorption using nZVI-SS biocomposite. The rate constant $k_{\mathrm{a}}$ computed from the intercept of the BDST plot characterizes the rate of solute transfer from the liquid phase to the solid phase [27]. The calculated $N_{0}$ and $k_{\mathrm{a}}$ were $16.67 \mathrm{mg} / \mathrm{L}$ and $-9.6514 \mathrm{~L} /(\mathrm{mg} \mathrm{min})$, respectively, at $10 \mathrm{ml} / \mathrm{min}$ and $10 \mathrm{mg} / \mathrm{L}$. If $k_{\mathrm{a}}$ is large, even a short bed will avoid breakthrough, but as $k_{\mathrm{a}}$ decreases, progressively longer bed is required to avoid breakthrough [31].

\section{Conclusions}

This study demonstrated that the nZVI-SS biocomposite could be used as an effective biosorbent for the treatment of MG-containing wastewater. The novel nZVI-SS biocomposite synthesized was characterized using SEM, XRD, DLS XRF and XANES. The packed bed investigation on the biosorption of MG onto nZVI-SS biocomposite revealed the importance of bed height, flow rate and inlet solute concentration on MG biosorption. The column performance was better at higher inlet concentration, while the lowest flow rate and bed depth favored the column biosorption. The increase in bed height resulted in the extension of the breakthrough time, whereas increase in flow rate down-regulated the breakthrough time. The column data were well described using Thomas and YoonNelson models. In addition, BDST model was successfully used to predict the breakthrough curves at different flow rates and inlet MG concentrations.

\section{References}

1. Srivastava S, Sinha R, Roy D (2004) Toxicological effects of malachite green. Aquat Toxicol 66:319-329

2. Culp SJ, Beland FA (1996) Malachite green: a toxicological review. J Am Coll Toxicol 15:219-238

3. Nigam P, Banat IM, Singh D, Marchant R (1996) Microbial process for the decolorization of textile effluent containing azo, diazo and reactive dyes. Proc Biochem 31:435-442

4. Tiravanti G, Petruzzelli D, Passino R (1997) Pretreatment of tannery wastewaters by an ion exchange process for $\mathrm{Cr}$ (III) removal and recovery. Water Sci Technol 36:197-207

5. Fu Y, Viraragavan T (2002) Removal of congo red from solution by fungus Aspergillus niger. Adv Environ Res 220:239-247

6. Baskar G, Pavithra SK, Sheraz FK, Renganathan S (2014) Optimization, equilibrium, kinetic modeling, and thermodynamic studies of biosorption of aniline blue by the dead biomass of Aspergillus fumigates. Desalin Water Treat 52:3547-3554

7. Khattri SD, Singh MK (1999) Adsorption of basic dyes from aqueous solution by natural absorbent. Indian $\mathrm{J}$ Chem Technol 6:112-116

8. Holan ZR, Volesky B, Prasetyo I (1993) Biosorption of cadmium by biomass of marine algae. Biotechnol Bioeng 41:819-825

9. Jerold M, Vigneshwaran C, Sivasubramanian V (2015) Macrophytes: a potent bio-sorbent for the sequestration of heavy metals. Int Adv Res J Sci Eng Technol 2:16-26

10. Jerold M, Vasantharaj K, Daisy J, Sivasubramanian V (2016) Fabrication of hybrid biosorbent nanoscale zero-valent ironSargassum swartzii biocomposite for the removal of crystal violet from aqueous solution. Int $\mathrm{J}$ Phytoremediat. doi:10.1080/ 15226514.2016.1207607

11. Sohrabi MR, Amiri S, Masoumi HRF, Moghri M (2014) Optimization of direct yellow 12 dye removal by nanoscale zerovalent iron using response surface methodology. J Ind Eng Chem 20:2535-2542

12. Frost RL, Xi Y, He H (2010) Synthesis, characterization of palygorskite supported zero-valent iron and its application for methylene blue adsorption. J Colloid Interface Sci 341:153-161 
13. Yuan-Pang S, Xiao-qin L, Jiasheng C, Wei-xian Z, Paul WH (2006) Characterization of zero-valent iron nanoparticles. Adv Colloid Int Sci 120:47-56

14. Liu YQ, Majetich SA, Tilton RD, Sholl DS, Lowry GV (2005) TCE dechlorination rates, pathways, and efficiency of nanoscale iron particles with different properties. Environ Sci Technol 39:1338-1345

15. Al-Degs YS, Khraisheh MAM, Allen SJ, Ahmad MN (2009) Adsorption characteristics of reactive dyes in columns of activated carbon. J Hazard Mater 165:944-949

16. Al-Qodah Z, Lafi W (2003) Continuous adsorption of acid dyes in fixed beds. J Water Supply Res Technol 52:189-198

17. Aksu Z, Gonen F (2004) Biosorption of phenol by immobilised activated sludge in a continuous packed bed: prediction of breakthrough curves. Proc Biochem 39:599-613

18. Charumathi D, Das N (2012) Packed bed column studies for the removal of synthetic dyes from textile wastewater using immobilised dead C. tropicalis. Desalination 285:22-30

19. Uddin MT, Rukanuzzaman MK, Islam MMR (2009) Adsorption of methylene blue from aqueous solution by jackfruit (Artocarpus heteropyllus) leaf powder: a fixed-bed column study. J Environ Manag 90:3443-3450

20. Baral SS, Das N, Ramulu TS, Sahoo SK, Das SN, Chaudhury GR (2009) Removal of Cr(VI) by thermally activated weed Salvinia cucullata in a fixed-bed column. J Hazard Mater 161:1427-1435

21. Gupta VK, Rastogi A, Nayak A (2010) Adsorption studies on the removal of hexavalent chromium from aqueous solution using a low cost fertilizer industry waste material. J Colloid Interface Sci 342:135-141

22. Ahmad AA, Hameed BH (2010) Fixed-bed adsorption of reactive azo dye onto granular activated carbon prepared from waste. J Hazard Mater 175:298-303
23. Kumar PA, Chakraborty S (2009) Fixed-bed column study for hexavalent chromium removal and recovery by short-chain polyaniline synthesized on jute fiber. J Hazard Mater 162:1086-1098

24. Bohart G, Adams E (1920) Some aspects of the behavior of charcoal with respect to chlorine. J Am Chem Soc 42:523-544

25. Guibal E, Lorenzelli R, Vincent T, Cloirec PL (1995) Application of silica gel to metal ion sorption: static and dynamic removal of uranyl ions. Environ Technol 16:101-111

26. Thomas HC (1944) Heterogeneous ion exchange in a flowing system. J Am Chem Soc 66:1664-1666

27. Hasan SH, Ranjan D, Talat M (2010) Agro-industrial waste 'wheat bran' for the biosorptive remediation of selenium through continuous up-flow fixed-bed column. J Hazard Mater 181:1134-1142

28. Yoon YH, Nelson JH (1984) Application of gas adsorption kinetics. I: a theoretical model for respirator cartridge service life. Am Ind Hyg Assoc J 45:509-516

29. Calero M, Hernáinz F, Blázquez G, Tenorio G, Martín-Lara MA (2009) Study of $\mathrm{Cr}$ (III) biosorption in a fixed-bed column. J Hazard Mater 171:886-893

30. Han RP, Wang Y, Zhao X, Wang YF, Xie FL, Cheng JM, Tang MS (2009) Adsorption of methylene blue by phoenix tree leaf powder in a fixed-bed column: experiments and prediction of breakthrough curves. Desalination 245:284-297

31. Cooney DO (1999) Adsorption design for wastewater treatment. CRC Press, Boca Raton, pp 137-172 